\title{
Knowledge, confidence and attitude of primary care doctors in managing in-flight medical emergencies: a cross-sectional survey
}

Wei Leik $\underline{\mathrm{Ng}^{1}}$, MBBS, MFamMed, Nurdiana $\underline{\mathrm{Abdullah}}{ }^{1}$, MBBS, MFamMed

INTRODUCTION Medical emergencies occur at a rate of one in 604-753 flights. Doctors travelling on commercial flights may encounter an in-flight medical emergency requiring their assistance. There is a paucity of studies on how confident primary care doctors are in managing in-flight medical emergencies. This study aimed to determine the knowledge, confidence and attitude of primary care doctors in managing in-flight medical emergencies.

METHODS A cross-sectional study was conducted on all primary care doctors working in government health clinics in Kuala Lumpur, Malaysia, from October 2016 to November 2016. A self-reported questionnaire was used, which included questions on demographic information, knowledge of in-flight medicine, and the attitude and confidence of primary care doctors in managing in-flight medical emergencies.

RESULTS 182 doctors completed the questionnaire (92.9\% response rate). The mean knowledge score was 8.9 out of a maximum score of 20 . Only $11.5 \%$ of doctors felt confident managing in-flight medical emergencies. The majority (69.2\%) would assist in an in-flight medical emergency, but the readiness to assist was reduced if someone else was already helping or if they were not familiar with the emergency. Total knowledge score was positively associated with confidence in managing in-flight medical emergencies $(p=0.03)$.

CONCLUSION Only one in ten primary care doctors in this study felt confident managing in-flight medical emergencies. A higher total knowledge score of in-flight medical emergencies was positively associated with greater confidence in managing them. Educational programmes to address this gap in knowledge may be useful to improve doctors' confidence in managing in-flight medical emergencies.

Keywords: confidence, in-flight medical emergencies, in-flight medical events, primary care physician

\section{INTRODUCTION}

In-flight medical emergencies (IMEs) have been reported to occur at a rate of one in 604-753 flights. ${ }^{(1,2)}$ Passenger doctors are often roped in to provide help during IMEs, in $43 \%-85 \%$ of reported incidents. ${ }^{(1,3,4)}$ Other studies on Good Samaritan acts by doctors showed that an airplane flight is a common setting for such acts. ${ }^{(5,6)}$

Common problems that occur on a flight include syncope or presyncope, respiratory symptoms, and gastrointestinal symptoms such as nausea or vomiting. ${ }^{(1,7,8)}$ There are some differences in the assessment and management of medical emergencies in-flight compared to incidents occurring on the ground owing to differences in the airplane cabin environment, such as lower barometric pressure, restricted cabin space and the limited equipment available on board an airplane.

Several published case reports have detailed doctors' experiences in dealing with IMEs. Challenges such as lack of expertise, uncertainty of diagnosis and management, the difficulty of managing patients in restricted surroundings and doubt regarding adequacy of care were raised. ${ }^{(9,10)}$ Bashir brought up the issue of doctors' initial hesitation to identify themselves, indicating a possible lack of readiness to face a medical emergency on board. ${ }^{(10)}$ Senior medical students' preparedness to respond to IMEs has also been studied, with Katzer et al showing in 2014 that they did not feel confident enough to manage IMEs. ${ }^{(2)}$
To date, no published study specifically examines the preparedness of doctors to manage IMEs. As primary care doctors, who are routinely exposed to multidisciplinary cases, are expected to manage IMEs more confidently, this study aimed to look into the knowledge, attitude and confidence of primary care doctors in this area.

\section{METHODS}

This was a cross-sectional study on primary care doctors working in government health clinics in Kuala Lumpur, Malaysia. Data was collected from October 2016 to November 2016. A selfreported questionnaire was used, consisting of questions on demographic information, knowledge of in-flight medicine and confidence in managing IMEs. The questionnaire was developed using a combination of literature review, guidelines on aviation medicine and a previous questionnaire by Katzer et al. ${ }^{(1,2,7,11-24)}$ The questionnaire underwent face and content validation to improve its relevance and clarity. The expert panel for content validation included a primary care medicine lecturer, two emergency physicians and three doctors specialising in aviation medicine.

During the study period, there were 203 primary care doctors working in government health clinics in Kuala Lumpur. 16 of them were family medicine specialists, while the rest were medical officers. Based on the Krejcie and Morgan sample size calculation 
formula for finite population, using the total population of 203 primary care doctors, a confidence level of $95 \%$, a $5 \%$ margin of error and a response distribution of $50 \%$, the minimum recommended sample size was 134 doctors. Universal sampling was used in this study.

The specific time for participant recruitment and questionnaire distribution was agreed upon in collaboration with the respective clinic head or administrator. The clinic head or administrator also provided the list of doctors working in each clinic and selected a representative from each clinic. The researcher briefed the representative on the study, and handed the questionnaire, participant information sheet and consent form to the representative to be distributed to doctors working in the respective clinics. The doctors could refuse to participate in the study, as stated in the participant information sheet. The participants were given one week to fill in the questionnaire. On the fifth day after the questionnaires were given to the representative, contact was made with the representative via text messaging to check on the progress and to set a time to collect the questionnaires.

Statistical analysis was performed using IBM SPSS Statistics for Windows, version 23.0 (IBM Corp, Armonk, NY, USA). Most of the variables in this study were categorical except for knowledge score, age, years of practice and duration of work in the emergency department (ED). For descriptive analysis of continuous variables, mean \pm standard deviation was used for data with a normal distribution (age and knowledge score), while median was used for data with a skewed distribution (years of practice and duration of work in the ED). Binary logistic regression was used to analyse the association of knowledge score and sociodemographic data with confidence in managing IMEs. A p-value $<0.05$ was considered significant. Data for confidence in managing IMEs was derived from Statement 8 in the self-assessment segment (on confidence responding to an IME). For binary logistic regression analysis, the five-point Likert Scale for Statement 8 was reorganised into 'confident' and 'others': the responses 'agree' and 'strongly agree' were collapsed into 'confident', while 'neither agree or disagree', 'disagree' and 'strongly disagree' were collapsed into 'others'. Knowledge score, years of practice and duration of work in the ED were analysed as continuous variables against confidence using binary logistic regression.

Ethics approval was obtained from the Medical Research and Ethics Committee (reference no. NMRR-16-1030-31343), Ministry of Health, Malaysia.

\section{RESULTS}

Out of the 203 doctors in government health clinics in Kuala Lumpur, 196 doctors were included in this study. Seven doctors were excluded as they were on long leave (maternity leave or long medical leave). 182 doctors completed the questionnaire, a $92.9 \%$ response rate. Most of the respondents were medical officers ( $\mathrm{n}=168,92.3 \%$ ) as opposed to family medicine specialists $(\mathrm{n}=14,7.7 \%)$, with a mean age of 33 years and median years of practice of six years. $81(44.5 \%)$ respondents had experience working in the ED, with a median duration of four months. Out of the 182 respondents, only $13(7.1 \%)$ had experience in providing assistance during IMEs. Almost all respondents had training in life support ( $\mathrm{n}=181,99.5 \%)$. Only $4(2.2 \%)$ respondents had received training in management of IMEs. In terms of frequency of air travel, the majority ( $\mathrm{n}=118,64.8 \%$ ) of the respondents travelled once a year or less, while $33.0 \%(n=60)$ of the respondents travelled two times per year or more. Only $4(2.2 \%)$ respondents had never travelled on an airplane.

The mean knowledge score was $8.9 \pm 3.3$ out of the maximum score of 20. The questions that were most commonly answered incorrectly was Question 8 (regarding a symptom of decompression sickness), Question 14 (iv) (whether the laryngoscope is a common equipment available on aircraft), Question 3 (whether commercial airplane cabins are pressurised to sea level altitude) and Question 10 (whether cardiac arrest is the most common IME). The question most frequently answered correctly was Question 7 (whether long-haul flights are associated with increased risk of venous thromboembolism). The full results for the knowledge questionnaire are shown in Table I.

Table II shows the attitude and confidence of primary care doctors in managing IMEs. Regarding the statement "I would currently feel confident responding to an IME and providing competent care", responses were mainly divided between 'disagree/strongly disagree' $(\mathrm{n}=83,45.6 \%)$ and 'neutral' $(\mathrm{n}=78$, $42.9 \%)$. Only $21(11.5 \%)$ respondents agreed with that statement (Table II). Most respondents said they would identify themselves as a doctor and offer assistance in the event of an IME (69.2\%). However, their willingness to assist fell (51.1\%) if there was already someone else offering assistance or if the doctors were not familiar with the nature of the emergency (58.2\%).

From the multiple logistic regression, only total knowledge score was found to be positively associated with confidence in managing IMEs ( $p=0.030$, Table III). With each additional score for knowledge questions, doctors were 1.2 times more likely to be confident. Years of practice, having the designation of family medicine specialist, experience in the ED, experience in managing IMEs and air travel frequency were not significantly associated with confidence in managing IMEs ( $p>0.05$, Table III).

\section{DISCUSSION}

Key findings from this study were: (a) the mean knowledge score was 8.9 out of a maximum score of 20; (b) almost $70 \%$ of the doctors were willing to provide assistance during IMEs, but the readiness to assist was less if someone else was already helping or if they were not familiar with the emergency; (c) few doctors were confident in managing IMEs; and (d) the knowledge score was associated with the participant's confidence in managing IMEs.

The mean knowledge score of 8.9 was less than $50 \%$ of the maximum score. This result did not reflect an overall satisfactory knowledge level. However, it is inadequate to conclude that the doctors had good or poor knowledge of managing IMEs. A proper validated knowledge questionnaire with a scoring system would be needed. One of the key concepts that differentiates medical emergencies occurring on board an airplane from those at ground 
Table I. Number of correct answers for each item in the knowledge questionnaire $(n=182)$.

\begin{tabular}{|c|c|c|}
\hline Question & Correct answer & No. (\%) \\
\hline \multicolumn{3}{|l|}{ Aviation physiology } \\
\hline 1. Cabin pressure leads to a decrease in systemic oxyhaemoglobin saturation. & True & $119(65.4)$ \\
\hline $\begin{array}{l}\text { 2. The humidity in cabin air on a commercial airline flight is typically relatively low when compared to } \\
\text { typical ground level building interiors. }\end{array}$ & True & $115(63.2)$ \\
\hline 3. Commercial airplane cabins are typically pressurised to an altitude of sea level. & False & $30(16.5)$ \\
\hline 4. Gas in body cavities can expand by $30 \%$ at low cabin pressure associated with cruising attitudes. & True & $50(27.5)$ \\
\hline \multicolumn{3}{|l|}{ Medical conditions affected by air travel } \\
\hline 5. Patient with acute exacerbation of asthma benefits from altitude restriction. & True & $54(29.7)$ \\
\hline $\begin{array}{l}\text { 6. Passengers with recent abdominal surgery are at risk of wound dehiscence or bowel perforation with } \\
\text { air travel. }\end{array}$ & True & $92(50.5)$ \\
\hline 7. Long haul flights are associated with increased risk of venous thromboembolism. & True & $171(94.0)$ \\
\hline $\begin{array}{l}\text { 8. The most common symptom of decompression sickness, which can happen to scuba divers if they fly } \\
\text { too soon after diving, is confusion. }\end{array}$ & False & $23(12.6)$ \\
\hline 9. Air travel is associated with increased risk of preterm labour. & False & $51(28.0)$ \\
\hline \multicolumn{3}{|l|}{ Epidemiology } \\
\hline 10. Cardiac arrest is the most common in-flight medical emergency. & False & $33(18.1)$ \\
\hline 11. Only a minority of in-flight medical emergencies result in diversion of the plane. & True & $100(54.9)$ \\
\hline \multicolumn{3}{|l|}{ Medicolegal issue } \\
\hline $\begin{array}{l}\text { 12. Medical doctors, who are passengers on commercial airplane, are obligated legally to respond to } \\
\text { in-flight medical emergencies in Malaysia. }\end{array}$ & False & $57(31.3)$ \\
\hline $\begin{array}{l}\text { 13. For flights on international airspace, the country where the aircraft is registered has legal jurisdiction on } \\
\text { whether medical doctors are legally obligated to provide assistance in in-flight medical emergencies. }\end{array}$ & True & $51(28.0)$ \\
\hline \multicolumn{3}{|l|}{ Equipment available } \\
\hline \multicolumn{3}{|l|}{ 14. Equipment contents of an aircraft medical kit would typically include: } \\
\hline (i) Sphygmomanometer & True & $129(70.9)$ \\
\hline (ii) Intravenous catheters & True & $122(67.0)$ \\
\hline (iii) Urinary catheter & True & $52(28.6)$ \\
\hline (iv) Laryngoscope & False & $22(12.1)$ \\
\hline \multicolumn{3}{|l|}{ 15. Drug contents of an aircraft medical kit would typically include: } \\
\hline (i) Epinephrine/adrenaline injectable & True & $120(65.9)$ \\
\hline (ii) Dextrose $50 \%$ injectable & True & $125(68.7)$ \\
\hline (iii) Oral aspirin & True & $129(70.9)$ \\
\hline (iv) Anticonvulsant injectable & True & $90(49.5)$ \\
\hline \multicolumn{3}{|l|}{ Support system } \\
\hline 16. Cabin crews are trained in basic life support. & True & $157(86.3)$ \\
\hline $\begin{array}{l}\text { 17. Most airlines provide in-flight medical consultation service with ground-based physicians in the event } \\
\text { of in-flight medical emergencies. }\end{array}$ & True & $95(52.2)$ \\
\hline $\begin{array}{l}\text { 18. The responding physician on board has the final say on whether the plane will be diverted because of } \\
\text { an in-flight medical emergency. }\end{array}$ & False & $36(19.8)$ \\
\hline
\end{tabular}

level is the differing barometric pressure in the cabin and the effect it would have on the human body. The respondents did not have a full understanding of this concept, as reflected in their answers to Questions 3-5 and Question 8 of the knowledge questionnaire. In terms of medicolegal issues, most of the respondents also answered incorrectly or were unsure for both questions (Questions 12 \& 13). This was in line with their responses to Statement 4 in the self-assessment questions, where a majority of respondents were afraid $(62.6 \%)$ or unsure $(21.4 \%)$ of the medicolegal implications that may arise from assisting in an IME. As a whole, in regard to the knowledge questionnaire, the doctors were unfamiliar with several specific issues in all domains. This gap in knowledge should be addressed to ensure a more complete understanding of in-flight medical issues among doctors.

It is reassuring to note that most respondents $(69.2 \%)$ in this study would agree to identify themselves as a doctor and offer assistance in the event of an IME. However, the willingness to assist was reduced $(51.1 \%)$ if there was already someone else offering assistance or if the doctors were not familiar with the nature of the emergency (58.2\%). This finding is in tandem with that of the North Carolina Good Samaritan study, where the most common reason for doctors not offering their help was that someone else had taken charge (42.2\% of all reasons) ${ }^{(6)}$ It is also not surprising to expect a reduction in willingness to assist if the 
Table II. Attitude and confidence of doctors regarding in-flight medical emergencies $(n=182)$.

\begin{tabular}{|c|c|c|c|}
\hline \multirow[t]{2}{*}{ Statement } & \multicolumn{3}{|c|}{ No. (\%) } \\
\hline & $\begin{array}{l}\text { Disagree/strongly } \\
\text { disagree }\end{array}$ & Neutral & $\begin{array}{l}\text { Agree/strongly } \\
\text { agree }\end{array}$ \\
\hline $\begin{array}{l}\text { 1. I would identify myself as a doctor and offer assistance in the event of an } \\
\text { in-flight medical emergency. }\end{array}$ & $10(5.5)$ & $46(25.3)$ & $126(69.2)$ \\
\hline $\begin{array}{l}\text { 2. I would stay out of an in-flight medical emergency if there is already } \\
\text { someone else offering their assistance. }\end{array}$ & $93(51.1)$ & $47(25.8)$ & $42(23.1)$ \\
\hline $\begin{array}{l}\text { 3. I would not offer assistance if I am not familiar with the nature of the } \\
\text { emergency, even though I am the only healthcare professional on board. }\end{array}$ & $106(58.2)$ & $48(26.4)$ & $28(15.4)$ \\
\hline $\begin{array}{l}\text { 4. I am afraid of the medicolegal implications which may arise from my } \\
\text { assistance at an in-flight medical emergency. }\end{array}$ & $29(15.9)$ & $39(21.4)$ & $114(62.6)$ \\
\hline 5. I need more training in managing in-flight medical emergencies. & $0(0)$ & $8(4.4)$ & $174(95.6)$ \\
\hline $\begin{array}{l}\text { 6. My medical training has given me adequate knowledge and skill to render } \\
\text { assistance during an in-flight medical emergency. }\end{array}$ & $93(51.1)$ & $68(37.4)$ & $21(11.5)$ \\
\hline $\begin{array}{l}\text { 7. My medical training has given me adequate knowledge and skill to render } \\
\text { assistance during a medical emergency on ground level. }\end{array}$ & $20(11.0)$ & $30(16.5)$ & $132(72.5)$ \\
\hline $\begin{array}{l}\text { 8. I would currently feel confident responding to an in-flight medical } \\
\text { emergency and providing competent care. }\end{array}$ & $83(45.6)$ & $78(42.9)$ & $21(11.5)$ \\
\hline $\begin{array}{l}\text { 9. I have adequate understanding of what medical supplies are available on } \\
\text { commercial airplanes. }\end{array}$ & $142(78.0)$ & $32(17.6)$ & $8(4.4)$ \\
\hline $\begin{array}{l}\text { 10. I have adequate understanding of the level of training of commercial air } \\
\text { crew in managing in-flight medical emergencies. }\end{array}$ & $139(76.4)$ & $32(17.6)$ & $11(6.0)$ \\
\hline $\begin{array}{l}\text { 11. I have an adequate understanding of the manner in which the air crew, } \\
\text { ground based medical control, and the on-board volunteer healthcare } \\
\text { provider collaborate to manage an in-flight medical emergency. }\end{array}$ & $128(70.3)$ & $41(22.5)$ & $13(7.1)$ \\
\hline
\end{tabular}

Table III. Multiple logistic regression for the association of sociodemographic variables and knowledge score with confidence in managing in-flight medical emergencies (IMEs).

\begin{tabular}{|c|c|c|c|}
\hline Variable & Adjusted OR & $95 \% \mathrm{Cl}$ & p-value \\
\hline Knowledge score & 1.204 & $1.018-1.424$ & $0.030^{*}$ \\
\hline Years of practice & 1.055 & $0.959-1.161$ & 0.272 \\
\hline \multicolumn{4}{|l|}{ Designation } \\
\hline Medical officer & 1 (ref) & & \\
\hline Specialist & 0.548 & $0.083-3.595$ & 0.531 \\
\hline \multicolumn{4}{|l|}{ Experience in ED } \\
\hline No & 1 (ref) & & \\
\hline Yes & 0.872 & $0.328-2.313$ & 0.782 \\
\hline \multicolumn{4}{|c|}{ Experience in assisting IME } \\
\hline No & 1 (ref) & & \\
\hline Yes & 1.550 & $0.342-7.028$ & 0.570 \\
\hline \multicolumn{4}{|c|}{ Frequency of air travel per year } \\
\hline Less than once/never & 1 (ref) & & \\
\hline Once & 2.174 & $0.537-8.794$ & 0.276 \\
\hline $2-3$ times & 2.964 & $0.697-12.601$ & 0.141 \\
\hline$>3$ times & 2.294 & $0.304-17.332$ & 0.421 \\
\hline
\end{tabular}

No multicollinearity was detected for all values. The regression model fit is acceptable based on Hosmer-Lemeshow test $(p=0.364)$ and classification table (overall correctly classified percentage $=88.5 \%$ ). ${ }^{*} \mathrm{~A} p$-value $<0.05$ was considered statistically significant. Cl: confidence interval; OR: odds ratio; ref: reference group

doctors were not familiar with the nature of the emergency. The authors of the North Carolina study had also postulated that the readiness of doctors to assist in Good Samaritan acts may vary depending on the nature of the emergency. ${ }^{(6)}$ The study found that the willingness to provide care differed depending on the nature of the care required. ${ }^{\left({ }^{6}\right)}$ Doctors may be hesitant to help if they are unfamiliar with the emergency, as they may be concerned that they would do more harm than good.

Despite the reduction in willingness to assist in specific circumstances, approximately $50 \%$ of the doctors in this study still agreed to offer assistance in IMEs. This could be due to their ethical obligation to offer their assistance. $89 \%$ of doctors in the North Carolina study believed that they had a moral obligation to assist in emergencies. ${ }^{(6)}$ However, as ours was a self-reported questionnaire, the respondents might have been inclined to give a more morally acceptable answer.

In terms of confidence in managing IMEs, the responses in our study were divided between not confident $(45.6 \%)$ and neutral $(42.9 \%)$, with only $11.5 \%$ of respondents feeling confident about it. It is interesting that although most respondents felt that they lacked understanding about IMEs and agreed that they needed more training, responses were divided when it came to confidence in managing such cases. Our initial hypothesis was that a vast majority of respondents would not feel confident in managing IMEs. One possible explanation is that most of the respondents in our study had never encountered an IME before, with only $7.1 \%$ of them having such experiences. Hence, they might have been unsure of what to expect and thus remained neutral about it. It is worth noting that the majority of our respondents travel via airplane once a year or less. This may explain the low rate of personal experience with managing IMEs in this study. 
The significant association between knowledge on IMEs and confidence in managing them in this study may lend some weight to the recommendation to improve doctors' knowledge in this field. However, increased confidence may not translate to better competency in managing IMEs. Further studies would be needed to demonstrate that point.

The strength of this study was the use of universal sampling and the good response rate of $92.8 \%$. There was also no prior similar study, to our knowledge. However, the study cannot be generalised to the entire population of primary care doctors in Malaysia, as it was only done in Kuala Lumpur and private general practitioners were not included. The accuracy of this study may be limited by the self-report nature of the questionnaire, which could have resulted in response bias. Doctors may have been inclined to give a more morally acceptable answer to some of the questions. Another limitation was that the participants who opted for 'neutral' in Statement 8 regarding confidence in managing IMEs were grouped together with those who were not confident in the outcome analysis. Behavioural theories, which may reveal other potential variables or confounding factors affecting doctors' confidence, were also not examined in this study. Proper validation of the knowledge questionnaire would be ideal and can be considered for future research. A larger population of doctors could be included for better generalisation.

In conclusion, only one in ten primary care doctors in this study felt confident when managing IMEs. The total knowledge score for IMEs was positively associated with greater confidence in managing them. Educational programmes to address this gap in knowledge may be useful to improve doctors' confidence in managing IMEs.

\section{REFERENCES}

1. Peterson DC, Martin-Gill C, Guyette FX, et al. Outcomes of medical emergencies on commercial airline flights. N Engl J Med 2013; 368:2075-83.

2. Katzer RJ, Duong D, Weber M, Memmer A, Buchanan I. Management of in-flight medical emergencies: are senior medical students prepared to respond to this community need? West J Emerg Med 2014; 15:925-29.

3. Hordinsky JR, George MH. Utilization of emergency medical kits by air carriers Aviation Medicine Reports, Report No: DOT/FAA/AM-91/2, March 1991 Washington: Federal Aviation Administration, Office of Aerospace Medicine, Civil Aerospace Medical Institute.

4. Cummins RO, Chapman PJ, Chamberlain DA, Schubach JA, Litwin PE. In-flight deaths during commercial air travel. How big is the problem? JAMA 1988; 259:1983-8.

5. Burkholder TW, King RA. Emergency physicians as Good Samaritans: survey of frequency, locations, supplies and medications. West J Emerg Med 2016; 17:15-7.

6. Garneau WM, Harris DM, Viera AJ. Cross-sectional survey of Good Samaritan behaviour by physicians in North Carolina. BMJ Open 2016; 6:e010720.

7. Sand M, Bechara FG, Sand D, Mann B. Surgical and medical emergencies on board European aircraft: a retrospective study of 10189 cases. Crit Care 2009; 13:R3.

8. Hinkelbein J, Spelten O, Wetsch WA, Schier R, Neuhaus C. Emergencies in the sky: in-flight medical emergencies during commercial air transport. Trends Anaesth Crit Care 2013; 3:179-182.

9. Kozarsky P. Lessons at 30,000 feet. J Travel Med 2012; 19:331-3.

10. Bashir T. Patients crash more than airlines: a medical emergency at 35,000 ft. J Community Hosp Intern Med Perspect 2014; 4:10.3402/jchimp.v4.24730.

11. Aerospace Medical Association. Medical emergencies: managing in-flight medical events. Available at: https://www.asma.org/asma/media/AsMA/ Travel-Publications/Medical\%20Guidelines/In-flight-medical-events-guidancedocument-revised-July-2016.pdf. Accessed December 13, 2016.

12. International Air Transport Association. Medical manual 2016. Available at: https://www.iata.org/publications/Documents/medical-manual.pdf. Accessed December 13, 2016.

13. Silverman D, Gendreau M. Medical issues associated with commercial flights. Lancet 2009; 373:2067-77.

14. Humphreys S, Deyermond R, Bali I, Stevenson M, Fee JP. Effect of high altitude commercial air travel on oxygen saturation. Anaesthesia 2005; 60:458-60.

15. Muhm JM, Rock PB, McMullin DL, et al. Effect of aircraft-cabin altitude on passenger discomfort. N Engl J Med 2007; 357:18-27.

16. British Thoracic Society Standards of Care Committee. Managing passengers with respiratory disease planning air travel: British Thoracic Society recommendations. Thorax 2002; 57:289-304.

17. Coker RK, Shiner RJ, Partridge MR. Is air travel safe for those with lung disease? Eur Respir J 2007; 30:1057-63.

18. World Health Organization. WHO Research into Global Hazards of Travel (WRIGHT) project 2007. Available at: http://www.who.int/cardiovascular_ diseases/wright_project/phase1_report/WRIGHT\%20REPORT.pdf. Accessed November 23, 2016.

19. Aerospace Medical Association. Medical guidelines for airline travel 2nd edition. Available at: https://www.asma.org/asma/media/asma/Travel-Publications/ medguid.pdf. Accessed June 20, 2016.

20. Royal College of Obstetricians and Gynaecologists. Air travel and pregnancy. Scientific Impact Paper No. 1, May 2013. Available at: https://www.rcog.org.uk/ globalassets/documents/guidelines/scientific-impact-papers/sip_1.pdf. Accessed November 21, 2016.

21. Gendreau MA, DeJohn C. Responding to medical events during commercial airline flights. N Engl J Med 2002; 346:1067-73.

22. Wallace WA. Training and equipment for in-flight medical emergencies. Conference paper presented at the International Conference on Cabin Safety Research, Atlantic City, New Jersey, USA, November 1995.

23. Medical Council of New Zealand. A doctor's duty to help in medical emergency. Available at: http://www.mcnz.org.nz/assets/News-and-Publications/ Statements/A-doctors-duty-to-help-in-a-medical-emergency.pdf. Accessed December 21, 2015.

24. Medical Defence Malaysia Berhad. Doctor as rescuer, good Samaritan or volunteer. Available at: http://www.mdm.org.my/archived_articles. php?newsID=3\&archived=yes. Accessed December 23, 2016. 